\title{
BMJ Open National optimisation of accessibility to emergency obstetrical and neonatal care in Togo: a geospatial analysis
}

\author{
Andrew Curtis, ${ }^{1,2}$ Jean-Pierre Monet, ${ }^{3}$ Michel Brun, ${ }^{3}$ \\ Issa Abdou-Kérim Bindaoudou, ${ }^{4}$ Idrissou Daoudou, ${ }^{5}$ Marta Schaaf (D) ,6 \\ Yawo Agbigbi, ${ }^{7}$ Nicolas Ray (1) ${ }^{1,2}$
}

To cite: Curtis A, Monet J$\mathrm{P}$, Brun $\mathrm{M}$, et al. National optimisation of accessibility to emergency obstetrical and neonatal care in Togo: a geospatial analysis. BMJ Open 2021;11:e045891. doi:10.1136/ bmjopen-2020-045891

- Prepublication history and additional supplemental material for this paper are available online. To view these files, please visit the journal online (http://dx.doi.org/10.1136/ bmjopen-2020-045891)

Received 15 0ctober 2020 Accepted 12 July 2021

\section{Check for updates}

(c) Author(s) (or their employer(s)) 2021. Re-use permitted under CC BY-NC. No commercial re-use. See rights and permissions. Published by BMJ.

${ }^{1}$ GeoHealth Group, Institute of Global Health, University of Geneva, Geneva, Switzerland ${ }^{2}$ Institute for Environmental Sciences, University of Geneva, Geneva, Switzerland

${ }^{3}$ Technical Division, UNFPA, New York, New York, USA

${ }^{4}$ National Institute of Statistics and Economic and Demographic Studies, Lomé, Togo

${ }^{5}$ Ministry of Health of Togo, Lomé, Togo

${ }^{6}$ Independent Consultant, Brooklyn, New York, USA ${ }^{7}$ UNFPA-Togo, Lomé, Togo

Correspondence to Professor Nicolas Ray; nicolas.ray@unige.ch

\section{ABSTRACT}

Objectives Improving access to emergency obstetrical and neonatal care (EmONC) is a key strategy for reducing maternal and neonatal mortality. Access is shaped by several factors, including service availability and geographical accessibility. In 2013, the Ministry of Health (MoH) of Togo used service availability and other criteria to designate particular facilities as EmONC facilities, facilitating efficient allocation of limited resources. In 2018, the MoH further revised and rationalised this health facility network by applying an innovative methodology using health facility characteristics and geographical accessibility modelling to optimise timely access to EmONC services. This study compares the geographical accessibility of the network established in 2013 and the smaller network developed in 2018.

Design We used data regarding travel modes and speeds, geographical barriers and topographical and urban constraints, to estimate travel times to the nearest EmONC facilities. We compared the EmONC network of 109 facilities established in 2013 with the one composed of 73 facilities established in 2018, using three travel scenarios (walking and motorised, motorcycle-taxi and walking-only). Results When walking and motorised travel is considered, the 2013 EmONC network covers $81 \%$ and $96.6 \%$ of the population at the 1-hour and 2-hour limit, respectively. These figures are slightly higher when motorcycle-taxis are considered ( $82.8 \%$ and $98 \%$ ), and decreased to $34.7 \%$ and $52.3 \%$ for the walking-only scenario. The 2018 prioritised EmONC network covers 78.3\% (1-hour) and $95.5 \%$ (2-hour) of the population for the walking and motorised scenario.

Conclusions By factoring in geographical accessibility modelling to our iterative EmONC prioritisation process, the MoH was able to decrease the designated number of EmONC facilities in Togo by about 30\%, while still ensuring that a high proportion of the population has timely access to these services. However, the physical access to EmONC for women unable to afford motorised transport remains inequitable.

\section{INTRODUCTION}

The Sustainable Development Goal 3 (SDG3) aims to better health outcomes for different at risk groups, including pregnant women (SDG3.1) and children under 5 years of age

\section{Strengths and limitations of this study}

- This is the first study presenting an improvement of a network of emergency obstetrical and neonatal care (EmONC) facilities, based on the characteristics of these facilities and on realistic physical accessibility modelling.

- Country-based experts estimated the modes and speeds of transport on the various road types and off-road landcover categories, and associated uncertainty analyses assessing relative effect of travel speeds were performed.

- The EmONC prioritisation approach succeeded in prioritising 73 out of the initial 109 EmONC facilities, with only a marginal drop of population coverage. This will enable efficient use of limited resources.

- Only the physical accessibility to nearest designated EmONC services was modelled, but potential financial barriers and the fact that some patients could opt to bypass the nearest facility may also affect access to EmONC.

- Travel was modelled only for the dry season conditions, but degraded road conditions in certain parts of the country during the wet season may affect our estimates of EmONC accessibility.

(SDG3.2). One of the primary strategies for reducing maternal and neonatal mortality and morbidity is ensuring timely access to quality emergency obstetrical and neonatal care (EmONC). ${ }^{1}$ However, access to EmONC is still a challenge in many low-income countries, especially in sub-Saharan Africa. ${ }^{2}$

Because the physical distance to facilities has long been recognised as an important component of timely access to care, ${ }^{34}$ an adequate geographical distribution of EmONC facilities is a prerequisite to minimise travel times for women in need of EmONC. The WHO recommends a benchmark of no more than 2 hours of travel time to reach the nearest EmONC facility, ${ }^{5}$ as after 2 hours, an obstetrical haemorrhage can be fatal. 
Realistically modelling and measuring spatial accessibility to health services is therefore very important for adequate planning and improvement of access to quality healthcare for pregnant women and newborns. ${ }^{6}$ Some studies have used simple distance ${ }^{7}$ and time $^{8}$ metrics, as well as population-to-provider ratios. ${ }^{9}$ These metrics have been popular for their ease of use and minimal need for the input of spatial data layers, that is, data that both provide locations and describe characteristics of geographical features. ${ }^{10}$

However, these methods are not appropriate for modelling geographical accessibility in complex terrains where different modes of transport are potentially used for a single trip, and when patients seeking care are facing an emergency, where every minute of travel time is consequential. In such cases, approaches based on least-cost path modelling (ie, finding the fastest route between locations based on various travel constraints) have proved useful to estimate time and routing to reach the nearest care providers, and to model catchment areas of facilities. ${ }^{10}$ Applying this modelling approach, the AccessMod tool ${ }^{11}$ helps estimate geographical accessibility by taking into consideration the modes of transport, their respective speeds of travel on roads and off-road on various landcover types and the influence of the topography and other barriers to movement. Studies assessing the accessibility of a variety of healthcare destinations have used AccessMod in their analyses. ${ }^{12-19}$ Specific to accessibility to EmONC, Ebener and colleagues ${ }^{20}$ have recently formalised and proposed new indicators based on least-cost path modelling.

The main objective of this study was to realistically determine and compare the overall geographical accessibility of our target population (women with obstetrical complications in need of EmONC) to two EmONC facility networks: the first one designated by the Ministry of Health $(\mathrm{MoH})$ in 2013 and the second one in 2018 through a methodology using accessibility modelling. The comparison of the two networks in terms of physical accessibility and population coverage is very useful in Togo, a country where (1) the probability of being attended at birth by qualified personnel is strongly linked to socioeconomic status and where (2) three-quarters of maternal deaths are due to direct obstetrical complications, ${ }^{21}$ which could for the most part be avoided if those experiencing complications have access to quality EmONC in less than 2 hours. We defined and applied various travel scenarios based on inputs from national and subnational stakeholders, including speed and transport modes and their associated uncertainties. Besides expanding knowledge on the underlying mechanisms of geographical access to EmONC facilities in Togo, we described a robust spatially-explicit methodology for quantifying the population covered by networks of EmONC health facilities that can be replicated in other countries.

\section{DATA AND METHODS}

\section{Study site and context}

Togo is one of the smallest African countries in terms of landmass (approximately $56785 \mathrm{~km}^{2}$ ), with a population of approximately 7.9 million in $2018,{ }^{22}$ and is bordered by Benin to the east, Ghana to the west and Burkina Faso to the north. More than $40 \%$ of the total population live in the southern part of the country (in the region of Maritime and in the capital city of Lomé), with $42 \%$ of this population living in urban areas. ${ }^{23}$ The 2017 Multiple Indicator Cluster Survey for Togo ${ }^{24}$ determined that there is a strong correlation between poverty and maternal mortality and morbidity. Indeed, the probability of giving birth assisted by qualified personnel is found to be highly correlated to socioeconomic status and to place of residence. The aforementioned survey determined that $98 \%$ of women in the richest quintile are assisted at birth by skilled health personal, compared with only $52 \%$ of the poorest quintile. It also highlighted the fact that $98 \%$ of women living in urban settings receive skilled birth attendance, as compared with $65 \%$ of women living in rural settings. Three-quarters of maternal deaths were found to be due to direct obstetrical causes. This suggests that access to timely EmONC is essential for reducing maternal mortality in Togo.

The 2017-2022 national plan for health sector development in Togo ${ }^{25}$ highlights that morbidity and mortality rates for mothers and newborns are still very high, and notes that this is due to insufficient supply of obstetrical and neonatal care and by barriers to service access, including financial barriers. Despite some progress over the last decades, maternal and newborn mortality are still high in Togo, respectively, with 396 (80\% CI: 270 to 557) maternal deaths per 100000 live births in $2017^{25}$ and 25 neonatal deaths per 1000 live births in 2018. ${ }^{2}$ Improving access to quality EmONC services has been a priority for the government since the EmONC needs assessment of 2012. In 2013, the MoH used facility data to identify 109 priority health facilities designated to provide EmONC services, and launched a process to monitor them on a quarterly basis to assess and address gaps in availability and quality of care. This national network encompassed both governmental and non governmental facilities, and its selection was done by considering several pieces of information on each facility: high obstetrical activity (ie, favouring those with more than 30 deliveries/month), qualified human resources, capacity to organise referrals, gaps in EmONC signal functions and adequate geographical distribution. EmONC facility functionality requires enough qualified providers for 24 hours $/ 7$ days services and the availability of key equipment, consumables and medication for performing the key medical interventions (or signal functions) that are used to treat the direct obstetrical complications that cause the vast majority of maternal deaths.

While the focus on a prioritised set of health facilities led to some progress in the availability of services, for example, the increase of the proportion of EmONC facilities applying vacuum extractions from $24 \%$ in 2014 to $43 \%$ in 2016, the $\mathrm{MoH}$ decided in 2018 to further focus their efforts and resource allocation by further decreasing the number of priority facilities; the $\mathrm{MoH}$ 
Table 1 Emergency obstetrical and neonatal care (EmONC) signal functions

\begin{tabular}{ll}
\hline Services available 24 hours/7 days \\
\hline $\begin{array}{ll}\text { Basic EmONC (BEmONC) } & \text { Comprehensive EmONC } \\
\text { signal functions } & \text { signal functions } \\
\text { 1. Administer parenteral } & \text { BEmONC signal functions } \\
\text { antibiotics } & (1-7)\end{array}$ \\
$\begin{array}{ll}\text { 2. Administer uterotonic } & + \\
\text { drugs } & \text { 8. Perform blood transfusion }\end{array}$ \\
$\begin{array}{ll}\text { 3. Administer parenteral } & \text { 9. Perform caesarean section } \\
\text { anticonvulsants } & \\
\text { 4. Perform manual removal } \\
\text { of the placenta }\end{array}$ \\
$\begin{array}{ll}\text { 5. Remove retained } \\
\text { products }\end{array}$ \\
$\begin{array}{l}\text { 6. Perform assisted vaginal } \\
\text { delivery }\end{array}$ \\
$\begin{array}{l}\text { 7. Perform basic neonatal } \\
\text { resuscitation }\end{array}$
\end{tabular}

ultimately selected 73 health facilities that should provide EmONC services in the country. This selection was guided by a methodology developed by United Nations Population Fund (UNFPA) and formalised and described in UNFPA's EmONC Network Development Implementation Manual. ${ }^{26}$ In brief, this methodology, based on WHO, UNFPA and UNICEF recommendations, ${ }^{5}$ helps countries to identify a network of EmONC facilities by selecting a number of EmONC facilities that do not exceed the international norm of five EmONC facilities per 500000 population and, by prioritising facilities that can most feasibly be supported to actually provide all the relevant EmONC signal functions 24 hours $/ 7$ days (see table 1 ) with quality care, during the next programmatic cycle of the $\mathrm{MoH}$ (ie, in the next 3-4 years). The selection of health facilities is done by considering both health facility characteristics (eg, number of deliveries, human resources, gaps in EmONC signal functions, infrastructure) and two spatially explicit indicators ${ }^{20}$ : the population living within 1-hour and/or 2-hour maximum travel time from the nearest EmONC facility (ie, population coverage), and the quality of each referral linkage between basic EmONC (BEmONC) health facilities and their closest comprehensive EmONC (CEmONC) health facility. BEmONC health facilities should provide seven EmONC signal functions 24 hours/ 7 days while CEmONC health facilities provide nine EmONC signal functions (see table 1). An EmONC facility is considered as functioning when it provides services 24 hours $/ 7$ days, and when it has performed all seven (BEmONC) or all nine (CEmONC) signal functions in the 3 months prior to data collection. ${ }^{5}$ A non-functioning EmONC facility has failed to provide one or more EmONC signal functions during that same period.

\section{Accessibility and population coverage modelling}

We used AccessMod, a WHO stand-alone and open-source geospatial tool, ${ }^{1127}$ to analyse the physical accessibility to, and the population coverage of, the national networks of EmONC health facilities in Togo in 2013 and 2018. AccessMod is based on a least-cost path algorithm that computes the fastest route between any location and the nearest health service (for details, see ${ }^{11}$ ). It can consider several sequential modes of travel (eg, walking to a road, where one catches a motorised vehicle), several types of barriers to movement, health facility capacity and population, when determining catchment areas. Moreover, AccessMod considers the direction of movement by applying an anisotropic analysis (ie, considering the slope of the terrain to accurately model bicycling and walking speeds). Contrary to many accessibility modelling approaches that are based on a perfectly routable road data set (such as Nichols $e t a l^{28}$ ), AccessMod can consider off-road travel in addition to road travel. On-road and off-road travel speeds and modes of transport are userdefined in a travel scenario that assigns these travel constraints to each land cover and/or road category found in the input data.

For the movements of our target population, we defined three distinct travel scenarios from home to the nearest EmONC facility: (1) a walking and motorised scenario, (2) a motorcycle-taxi scenario and (3) a walking-only scenario. The first scenario assumes that patients walk to the nearest road and then use a motorised mode of transportation (car, minibus or other motorised vehicle, either private or public), immediately available, to continue their journey. In the second scenario, patients use only a motorcycle-taxi to travel on-road and off-road, with different speeds depending on the land cover. Finally, the third scenario assumes patients are walking or being carried (eg, on stretchers, carts) at walking speed (or lower).

The choice for these three scenarios and their associated modes and speeds of travel were decided through an iterative process of two workshops in Togo in 20162018. A first 3-day workshop took place in May 2016 to strengthen national capacity to analyse the geographical accessibility of health facilities in Togo by using AccessMod. The 30 Togolese participants were technical experts from the $\mathrm{MoH}$, the national Togolese Institute for Statistics, Economic and Demographic studies (INSEED), non-governmental organizations, United Nations (UN) agencies and other key stakeholders (eg, regional health director, monitoring expert) from all regions of Togo. The pool of experts discussed and agreed on the specifics of how women with obstetrical emergency typically travel when they need to reach an EmONC facility in Togo. Average speeds of travel on all road categories were estimated by consensus, with the walking and motorised scenario deemed to be the most frequent. During a second workshop in May 2018, health stakeholders from each of the six regions of Togo gathered to define which health facilities should comprise their EmONC facility regional network, using the prioritisation methodology described above to select a number of EmONC facilities per region not exceeding the international norm of five 
EmONC facilities per 500000 population. These participants further refined the travel scenarios, and agreed that bicycles and public transport were rarely used, with the exception of a public bus system operating in greater Lomé. ${ }^{29}$ In both workshops, participants recognised that during the wet season the speeds of travel generally decrease in many areas. However, they decided to use only a dry season scenario to guide planning as this is the longest season in Togo, around 8 months. The final travel speeds chosen for the three scenarios are found in online supplemental file 1 .

Road speeds in urban areas were adjusted in order to simulate slower motorised travel occurring in intra-urban contexts due to various factors such as stoplights, traffic, pedestrians and other hazards. For the walking and motorised scenario, we lowered travel speeds on asphalted roads, secondary roads and tracks to $40 \mathrm{~km} /$ hour, $30 \mathrm{~km} /$ hour and $10 \mathrm{~km} /$ hour, respectively. For the motorcycletaxi scenario, these average travel speeds were lowered to $30 \mathrm{~km} /$ hour, $15 \mathrm{~km} /$ hour and $10 \mathrm{~km} /$ hour. These speed corrections were applied on all road segments falling within the extent of the urban areas informed by the Global Rural-Urban Mapping Project. ${ }^{30}$

\section{Uncertainty analysis}

To account for uncertainty in travel speeds, we additionally ran each consensus travel scenario with $20 \%$ slower or $20 \%$ faster speeds compared with the consensus scenario, following the methodology developed in Ouma $e t a l^{17}$ and in Stewart $e t a \hat{l}^{11}$. This translated to lower and upper uncertainty bounds on the reported output statistics. To further disentangle the effects of uncertainties on the speeds on roads and off roads, we ran scenario 1 by keeping on-road speeds constant (at consensus values) and varying off-road speeds by the plus or minus $20 \%$. Conversely, we ran this scenario keeping off-road speeds constant and varying on-road speeds. Finally, to test the model's sensitivity to the consideration of topography, we also ran each consensus travel speed scenario without considering slope correction (ie, isotropic mode).

Two uncertainty indicators were produced: (1) lower and upper uncertainty bounds on the variation in percentage (per region and for the whole country) of the coverage of population living less than 1 hour and less than 2 hours away from the closest EmONC facility, and (2) a series of spatially-explicit uncertainty maps. In these uncertainty maps, pixel values indicate the extent of the uncertainty of travel time to the nearest EmONC facility, obtained by subtracting the travel time grid resulting from the '-20\%' travel speeds scenario by the one resulting from the ' $+20 \%$ ' travel speeds scenario. This highlights the areas in the country where the travel time estimates have the most uncertainty.

\section{Input geospatial data}

Various data sets were assembled and prepared to run the geospatial analyses in AccessMod. Details of the preparation steps are found in online supplemental file 2. We considered barriers to terrestrial movements composed of quarries and bodies of water, such as rivers, lakes and damned areas. The barriers file was created by the Togolese Ministry of Agriculture, Livestock and Hydraulics ${ }^{32}$ (figure 1A). We used the road network created by the Direction de la Cartographie nationale et du cadastre of Togo, classified in three hierarchical categories: asphalted roads, secondary roads and tracks ${ }^{33}$ (figure 1B). We obtained the Digital Elevation Model (DEM) of Togo from NASA' Shuttle Radar Topography Mission ${ }^{34}$ (figure 1C). Slopes were derived from the DEM directly in AccessMod.

We used the population density data set from the Worldpop project, ${ }^{35}$ provided with UN-adjusted population count from 2013 (figure 1D) and 2018 (figure 1E). We assumed that the target population of women with obstetrical complications is uniformly distributed across the overall population. Land cover information was provided by INSEED, with a land cover data set composed of 12 categories (figure 1F). We obtained the names and geographical coordinates of the $109 \mathrm{EmONC}$ facilities composing the initial national network of EmONC health facilities in 2013 from INSEED (figure 1G). We further verified these names and coordinates with the help of the MoH. For the EmONC health facilities network of 2018 (figure 1H), the final designated set of 73 facilities was obtained through the $\mathrm{MoH} \cdot{ }^{36}$ Finally, the most recent administrative boundaries at the prefectural, regional and national levels were created and made available by INSEED using data collected during the 2010 general census $^{37}$ (see figure 1I). These data sets were used to determine the percentage of population coverage for each administrative unit.

\section{Patients and the public involvement}

There was no patient or public involvement in this study. Health facility names and geographical coordinates, as well as administrative boundaries, were shared by INSEED. The road network was shared by the Direction de la Cartographie nationale et du cadastre of Togo. The barriers to movement data sets were provided by the Ministère de l'agriculture, de la production animale et halieutique. All other geospatial data were publicly available.

\section{RESULTS}

The accessibility maps for the walking and motorised scenario, and the motorcycle-taxi scenario, and for the two time periods, are shown in figure 2 , with the respective maps for the walking-only scenario in online supplemental file 3. In 2013, estimated physical access was highest under scenario 2 (motorcycle-taxi scenario), with $82.8 \%$ of the total population less than 1 hour away from the nearest EmONC health facility and $98 \%$ less than 2 hours away from the nearest EmONC health facility. For the walking and motorised scenario, these estimations are $81 \%$ at the 1-hour travel time limit and $96.7 \%$ at the 2-hour limit, respectively. 


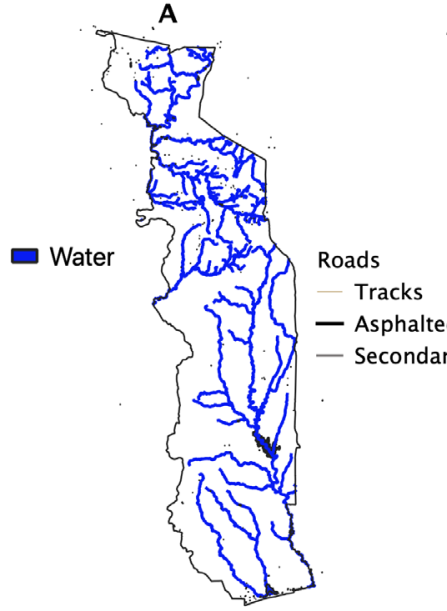

$\mathbf{F}$

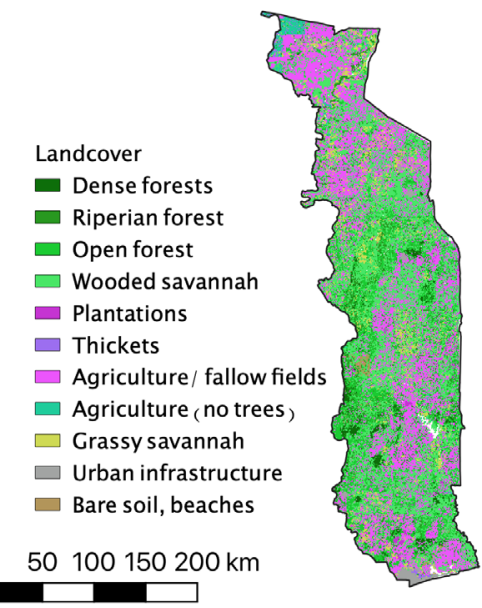

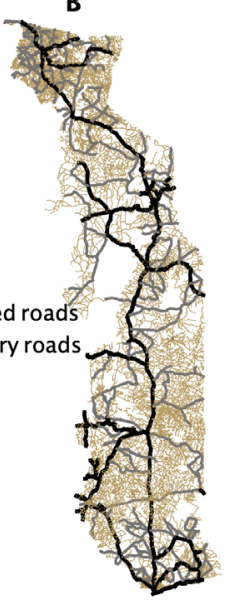

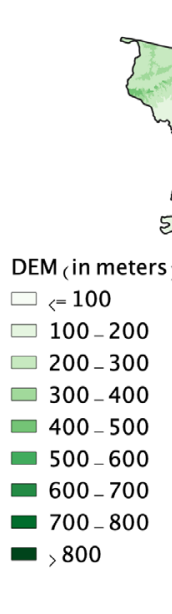

G

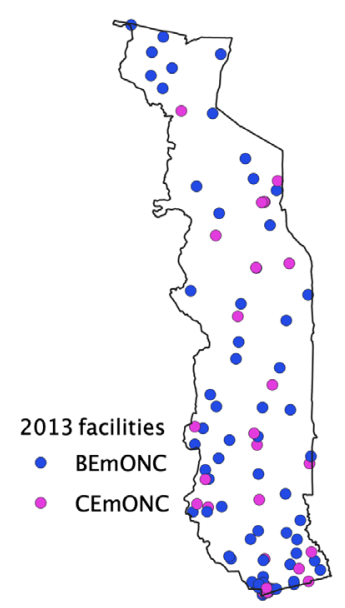<smiles>C1CC2CCC2C1</smiles>

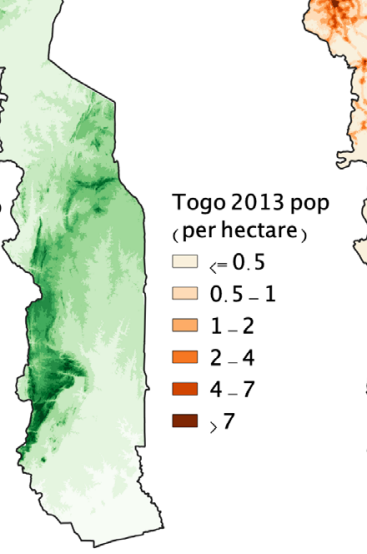

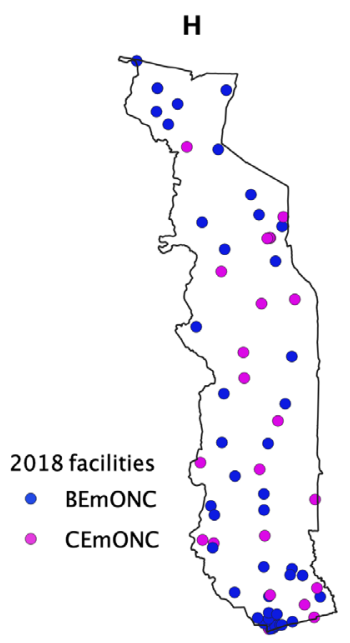

D
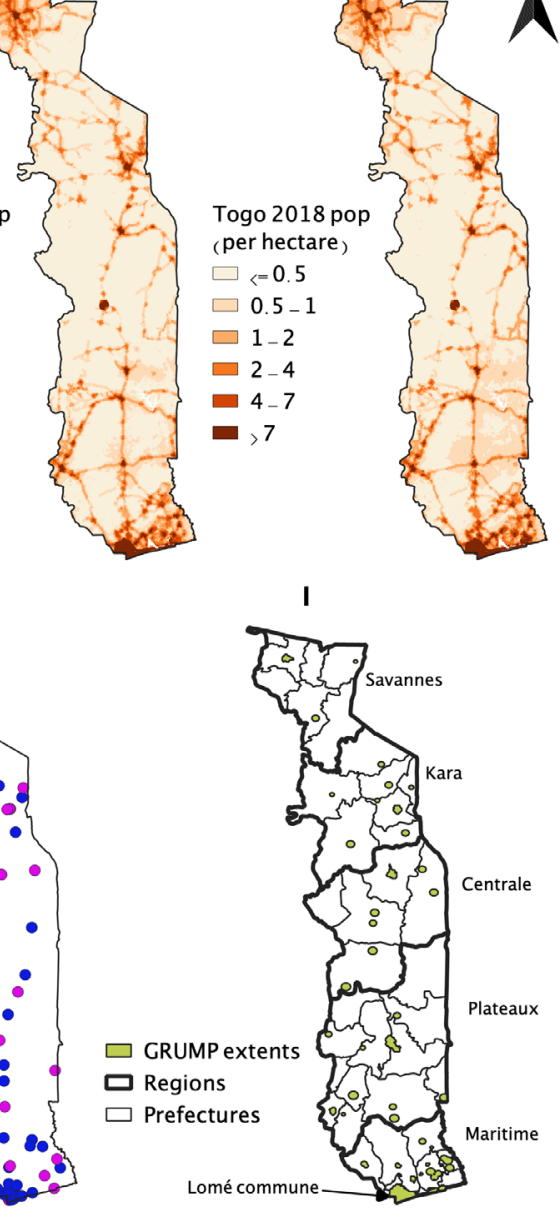

Figure 1 Vector and raster data sets used. (A) Barriers to movement (rivers, waterbodies, lakes); (B) road network; (C) Digital Elevation Model (DEM); (D) 2013 population density raster; (E) 2018 population density raster; (F) landcover raster; (G) 2013 EmONC facilities; (H) 2018 EmONC facilities; (I) administrative boundaries (prefectures, regions and Global Rural-Urban Mapping Project (GRUMP) urban extents) with region names. BEmONC, basic EmONC; CEmONC, comprehensive EmONC; EmONC, emergency obstetrical and neonatal care.

Using the 2018 network of 73 facilities, population coverages using the motorcycle-taxi scenario are $79.2 \%$ at the 1-hour travel time limit and of $96 \%$ at the 2-hour limit. Compared with the 2013 network, these population coverages are lower by $3.6 \%$ (of the total population) at the 1-hour threshold and by $2 \%$ at the 2 -hour limit. With the walking and motorised scenario, the corresponding results are $78.3 \%$ at the 1 -hour limit and $95.5 \%$ at the 2-hour limit. Compared with the initial estimations for the 2013 network, population coverage for that scenario has only dropped by $2.7 \%$ and $1.2 \%$, respectively. Despite a reduction of the number of EmONC health facilities by one-third from 2013 to 2018, the population able to physically access the closest EmONC health facility within 1 or 2 hours is only marginally lower compared with the 2018 prioritised network.

For both time periods, population coverage at national scale is only marginally higher for the motorcycle-taxi travel scenario when comparing to the walking and motorised scenario, even though this translates to a much larger extent of the country's surface under the 2-hour maximum travel time limit (green areas in figure 2). We also see that accessibility is highly dependent on roads in scenario 1. This is the case for instance in parts of the Atacora mountains (large red areas in the central-western part of the country in figure 2), a region with a very low population density and almost no roads (according to our data). With scenario 2, travel is less dependent on roads than in scenario 1 , but access tends nevertheless to be higher around the road network, even though travel speeds on roads are lower for the motorcycle-taxi scenario than for the walking and motorised scenario. The results for the 2018 network at regional level are given in table 2, and at prefectural level in online supplemental file 2.

The region of Lomé Commune has $100 \%$ population coverage for both time thresholds and both motorised scenarios, which is due to the combined effect of a very densely populated region of only $90 \mathrm{~km}^{2}$ with $11 \mathrm{EmONC}$ facilities in 2018, and a good road network that permits the Lomé population to access the closest EmONC in less than 1 hour travel time. In contrast, the rural region of Plateaux presents much more heterogeneous results, 


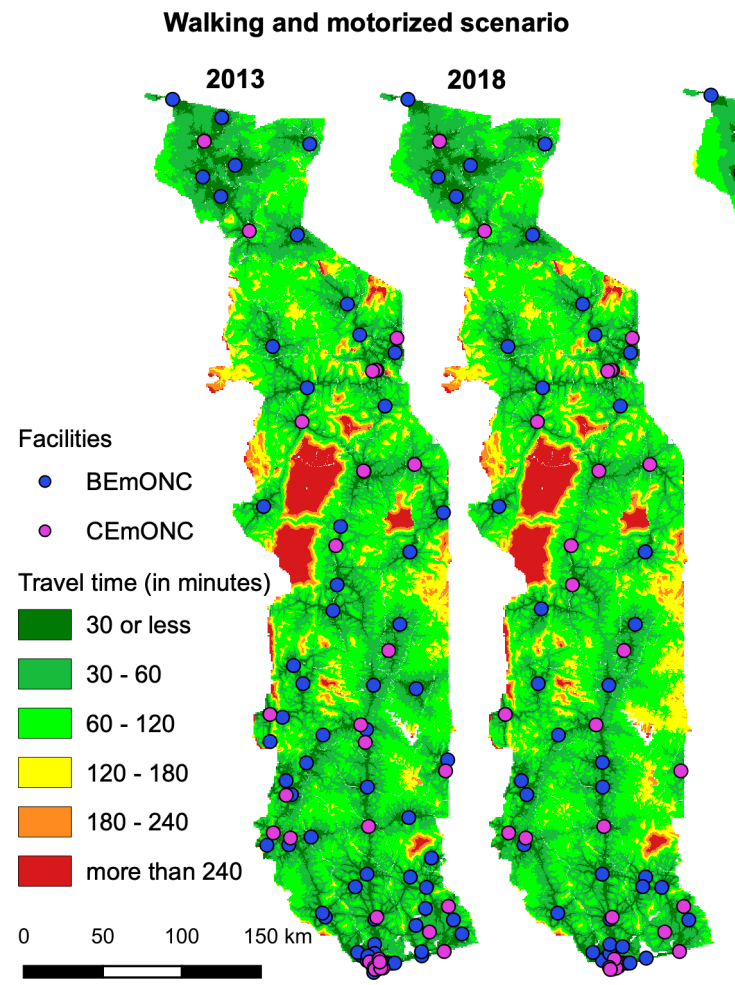

Motorcycle-taxi scenario

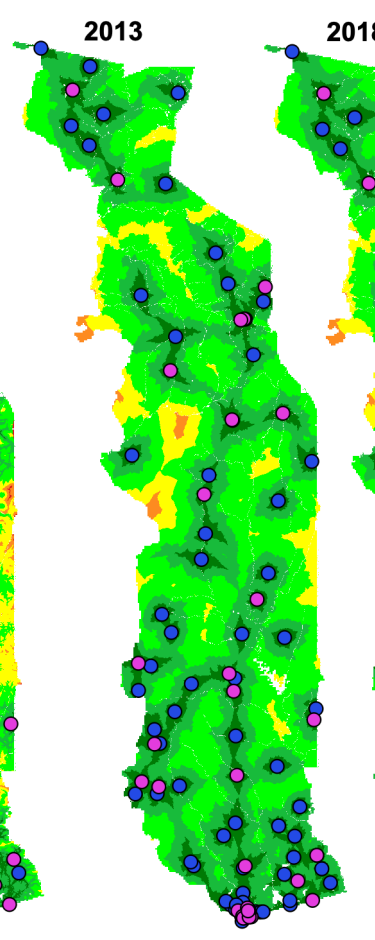

018

Walking-only scenario

A

motorcycle-taxi scenario and the walking-only scenario, for both time periods (2013 and 2018). BEmONC, basic EmONC; CEmONC, comprehensive EmONC; EmONC, emergency obstetrical and neonatal care.

with large uncertainty intervals. The results at prefectural level are available in online supplemental file 3.

We illustrate in figure 3 the uncertainty in travel time for the walking and motorised scenario on the 2018 facility data set, separated for the effects of speed uncertainty on roads and landcover. The maps show a spatially heterogeneous distribution of the uncertainties, especially in the case of the road speed uncertainty map with widespread uncertainties in all areas of the country, but with relatively low uncertainties along the asphalted road network. Similar maps for the uncertainty linked to the DEM are found in online supplemental file 4.

The landcover and road uncertainty maps show that uncertainty is strongest in areas with very little population density (see figure $1 \mathrm{E}$ ). The total uncertainty map, combining uncertainty from roads and landcover, further highlights the fact that uncertainty is quite low on roads close to facilities and increases in more rural areas.

As expected for the walking-only scenario, national population coverage of the 2018 network notably drops to $33.4 \%$ within 1 -hour walking and $50.8 \%$ within 2-hour walking. Large differences in coverage are found between regions, with the southern more urban regions of Lomé and Maritime achieving higher accessibility results than the more rural areas of the country. Indeed, while the two aforementioned regions reach coverage percentages of $100 \%$ and $76.4 \%$, respectively, at the 2-hour threshold, the coverage percentages do not exceed $40 \%$ for all the other modelled regions.

Table 2 Percentage of population living less than 1-hour or 2-hour travel time to the nearest emergency obstetrical and neonatal care facility, in 2018, per region and for the country, with uncertainty intervals within brackets

\begin{tabular}{|c|c|c|c|c|c|c|}
\hline \multirow[b]{2}{*}{ Region } & \multicolumn{2}{|c|}{ Walking and motorised scenario } & \multicolumn{2}{|c|}{ Motorcycle-taxi scenario } & \multicolumn{2}{|c|}{ Walking-only scenario } \\
\hline & 1-hour & 2-hour & 1-hour & 2-hour & 1-hour & 2-hour \\
\hline Plateaux & $55.4(44.4-65.1)$ & $89.8(80.7-95.2)$ & $58.7(49.2-66.3)$ & $88.4(78.5-94.6)$ & $10.9(8.3-13.3)$ & $22.6(18.1-27.2)$ \\
\hline Kara & $62.7(52.3-71)$ & $90.2(82.8-94.1)$ & $65.2(56.7-72)$ & $92.8(84-97.7)$ & $14.5(11-17.8)$ & $29.3(23.9-34.7)$ \\
\hline Maritime & $94.4(90.1-96.7)$ & $99.4(98.6-99.7)$ & $96.9(93.7-98.5)$ & $99.9(99.7-100)$ & $47.7(36.7-57)$ & $76.4(70.2-80.9)$ \\
\hline Centrale & $65.2(53-74.7)$ & $91.7(86.6-93.9)$ & $66.5(56.1-75.7)$ & $96.2(90-98.5)$ & $18.1(12.6-23.4)$ & $35.7(31.3-38.7)$ \\
\hline Savanes & $80.7(68.9-87.9)$ & 98.9 (96-99.6) & $72.5(58.9-81.8)$ & $97.9(93.3-99.9)$ & $11.4(8.4-14.2)$ & $24.2(19.1-30)$ \\
\hline Lomé Commune & $100(100-100)$ & $100(100-100)$ & $100(100-100)$ & $100(100-100)$ & $100(93.9-100)$ & $100(100-100)$ \\
\hline Country & $78.3(70.5-84)$ & $95.5(91.6-97.5)$ & $79.2(72.2-84.3)$ & $96(91.6-98.4)$ & $33.4(27.1-38.4)$ & $50.8(46-55)$ \\
\hline
\end{tabular}


A

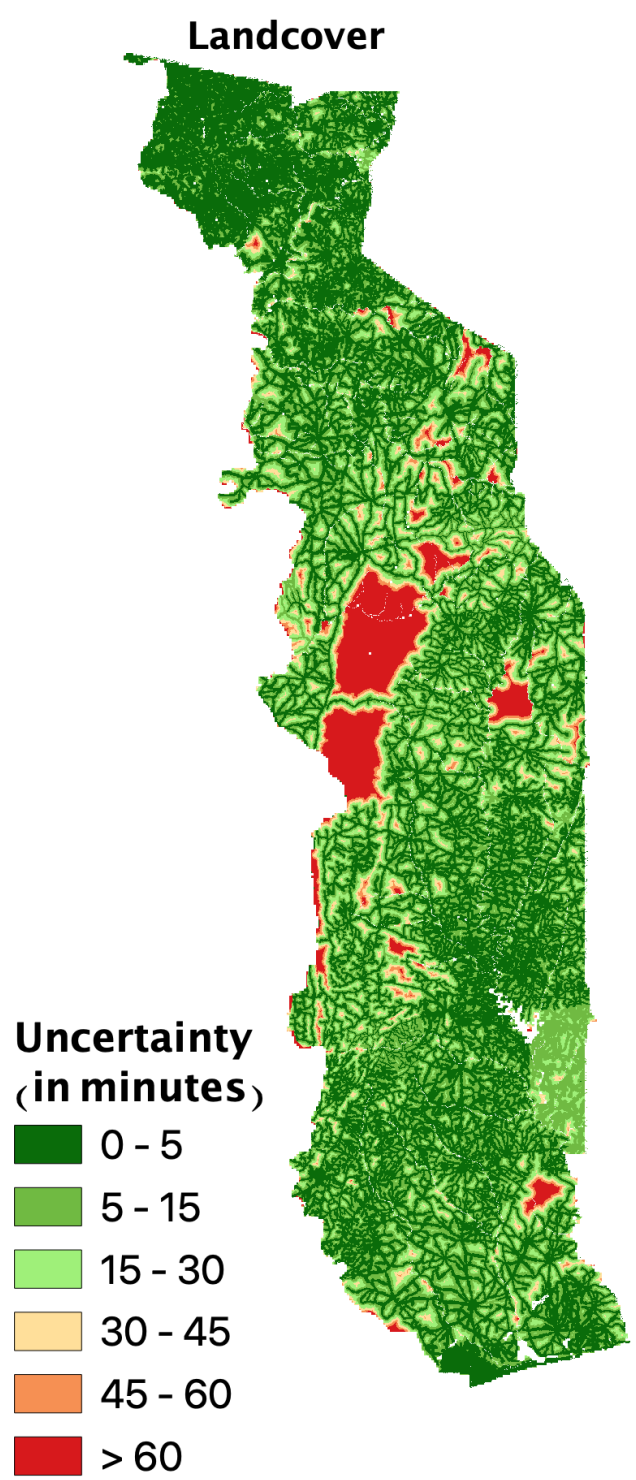

B

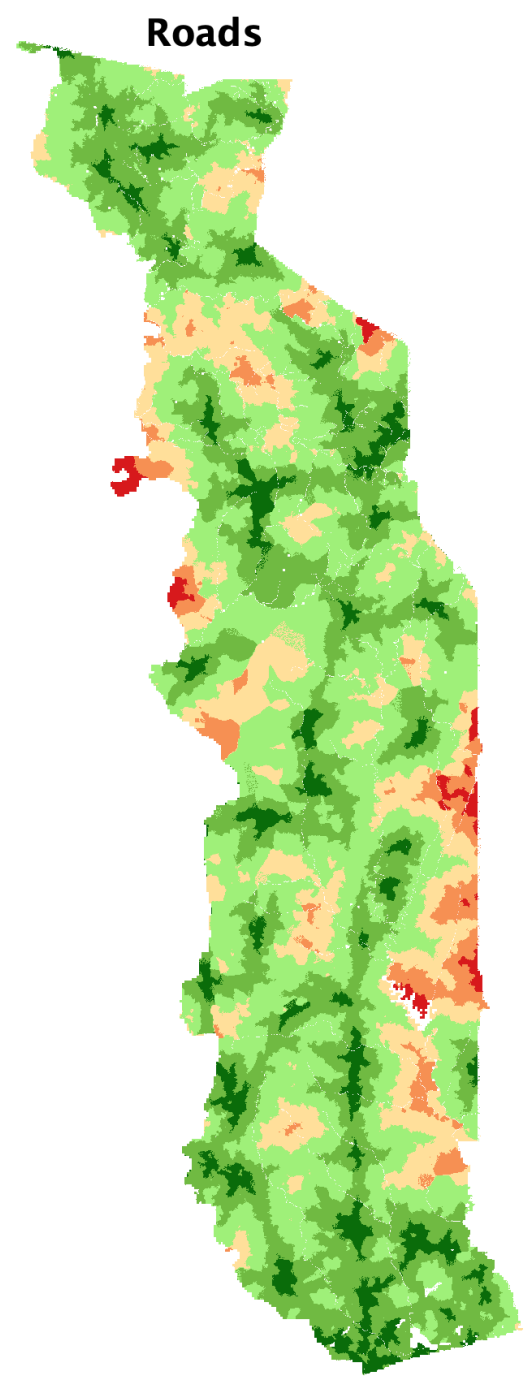

C

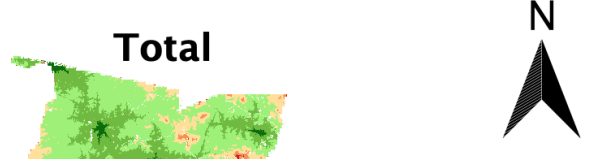

Figure 3 Uncertainty maps of the travel times to the nearest facility for the walking and motorised scenario on the 2018 EmONC facility network using (A) road uncertainty, (B) landcover (off-road) uncertainty and (C) total uncertainty. EmONC, emergency obstetrical and neonatal care.

\section{DISCUSSION}

The accessibility maps that were produced according to our three travel models illustrate the differences in accessibility in different parts of the country. This can help identify areas in the country where geographical accessibility to EmONC facilities is most difficult. These areas could be targeted for remedial efforts, such as mobile outreach, posting community health workers for reducing decision time to seek care, the creation of maternity waiting homes in the EmONC health facilities of the region or planning improvement of the road infrastructure.

The three alternative models used to obtain these maps reflect different socioeconomic segments of the population. If patients can afford to take a motorised vehicle after having reached the closest road or use a motorcycle-taxi from their home, then more than $78 \%$ of the population can reach the closest EmONC facility (as per the 2018 designation) in less than 1 hour. When considering 2-hour maximum travel time, this percentage is much higher, with $95 \%$ of the population able to reach the nearest facility within the time limit. We also note that the motorcycle-taxi scenario covers much larger areas of the country (green areas in figure 2 ) in comparison to the walking andmotorised scenario. Nevertheless, this does not result in a substantial increase in population coverage. This is explained by the fact that many areas where access is very low in scenario 1 are fairly unpopulated.

For women who have no access to motorised means of transport, accessibility to EmONC within 1 hour drastically decreases to about $33 \%$ of the population, and to $51 \%$ within the 2-hour threshold travel time limit. Thus, nearly half of the target population does not have access 
to EmONC in the maximum acceptable travel time if they cannot afford to travel by motorised means of transport. As anticipated, access to EmONC is greater for urban populations, even with substantially decreased travel speeds, due to a higher density of both EmONC facilities and road networks in urban areas.

Though the 2018 prioritised EmONC network included 36 fewer facilities than the 2013 network, the 2018 network still achieves high overall geographical accessibility, with all regions obtaining estimated coverage percentage of $90 \%$ and more. It only drops marginally in terms of population coverage (between 1\% and 3.6\% points depending on the scenario) when compared with the initial network of 109 designated EmONC facilities in 2013. However, from a planning perspective, prioritising the EmONC functionality of 73 , rather than 109, facilities is a more feasible, achievable goal for the next $\mathrm{MoH}$ programmatic cycle (ie, 3-4 years). The number of prioritised EmONC facilities is lower than the international norm that targets around 80 functional EmONC facilities for the 2018 population of Togo. However, the decision of the MoH to target this prioritised network was commensurate with available resources and the modelling results showing that this network can nevertheless ensure timely access to a large proportion of the population in case of obstetrical complications.

Our uncertainty analysis has shown that population coverage estimates are also most sensitive to uncertainties on the speeds on roads, as compared with the speeds off roads. This highlights the need for great caution when choosing travel speeds. A good representativeness of local experts, both in terms of knowledge about the specific travel behaviours of the target population and in terms of possible regional specificities for travel is vitally important. Other sources of information on effective travel speeds (eg, using speed tracker onboard vehicles or mobile phones) could be very useful if available in the future. Furthermore, spatially displaying the uncertainty regarding travel times highlights the regions where this uncertainty is the highest, and that could be given high priority for future improvements of model parametrisation. These improvements can be achieved by ensuring that all roads are well captured, or incorporating possible region-specific alternative means of transport.

\section{Limitations}

Although our study has produced the first high-resolution model of geographical accessibility to EmONC facilities in Togo, several limitations should be noted. First, our models only consider physical accessibility of the national network of EmONC health facilities. Although the three alternative transport models were created to acknowledge that motorised travel is not financially possible for some, there are additional financial barriers-such as formal and informal expenditures for healthcare-that our models do not address. Acceptability (ie, 'the match between how responsive health service providers are to the social and cultural expectations of individual users and communities', as mentioned in Peters $e t a l^{38}$ ) was also not considered. Immediate availability of motorised transport was also assumed in our models, which could overestimate accessibility in cases where delays for finding transport are significant. Variable quality of interpersonal and clinical care in facilities can also affect which facility patients chose; they may not choose the closest facility in terms of travel time, ${ }^{39}$ possibly bypassing BEmONC health facilities in certain cases. We also assumed no delay in the decision to seek care. Clearly, further research on how to incorporate these other facets of accessibility could improve our models and our understanding of the spatial variability of effective access to EmONC.

Second, the workshop participants decided to model travel during the dry season conditions. The extent of the degradation of road conditions could not be captured in certain parts of the countries during the wet season, and this is known to heavily affect travel time. A more balanced view of regional accessibility to EmONC could be achieved by factoring in these seasonal specificities.

Third, our analyses were built on a uniform uncertainty range $( \pm 20 \%)$ on all roads and landcover categories. This could be improved by applying parameter-specific uncertainty ranges, notably on the different road types. This could be captured by a dedicated workshop with regional experts having a thorough knowledge of the road network, providing more realistic uncertainty ranges on motorised and walking speeds, possibly complemented by field observations or facility-based surveys. Lowering uncertainties on the travel scenario, and therefore on population coverage estimates, would improve decisionmaking for prioritised resource allocation.

Finally, we analysed the coverage to the closest designated EmONC health facilities, which includes facilities that are actually functioning (as per our definition of functionality), as well as those that are not. The quarterly monitoring of the national network of EmONC health facilities in Togo started in 2015, and was included in the health management information system in 2020. This provides up-to-date information on the functionality of EmONC health facilities. The aim is to attain a network of functioning EmONC facilities, which is essential to help decrease maternal mortality/morbidity. Applying the same modelling approach described here to only functioning EmONC facilities would provide up-to-date population coverage indicators at national and subnational level that can inform decision-makers regarding the remaining gaps in order to optimise resource allocation. This will be the subject of a forthcoming publication.

\section{CONCLUSION}

The physical accessibility mapping of the national network of EmONC health facilities in Togo proved to be very useful in understanding the potential of the revised network to provide quality EmONC services to a large proportion of the population, while pointing to those areas with less accessibility. Using realistic 
modelling based on travel times, the accessibility analyses provided key information to the 2018 EmONC prioritisation exercise, which aimed at finding a balance between designating a smaller number of facilities as EmONC to channel needed resources to these priority sites for improving quality of care, and ensuring good coverage of the population within 1 hour of travel time to the closest designated EmONC health facility.

The application of this methodology in Togo can be replicated in other countries thanks to the current online availability of key high-resolution geospatial data sets. This is of particular importance where mapping of physical accessibility is a crucial component for bettering health outcomes for women and newborns.

Acknowledgements We thank the Ministry of Health (Ministère de la santé et de la protection sociale) of Togo for their engagement in the implementation of the EmONC facility network in Togo, INSEED for help in data preparation and UNFPATogo and UNFPA Maternal Health Thematic Fund for organising the workshops. We are grateful to Michelle Schmitz and Orvalho Augusto for their careful review of an earlier version of the manuscript. The authors express their gratitude to all workshop attendees, whose active participation contributed to informing the accessibility models. The Averting Maternal Death and Disability (AMDD) programme at the Columbia University Mailman School of Public Health provided technical support; Marta Schaaf worked at AMDD at the time this work was undertaken

Contributors AC: conceptualisation, methodology, formal analysis, writing, editing, visualisation, validation. J-PM: methodology, writing, editing, validation. MB: methodology, writing, editing, validation, supervision. IA-KB: data sharing, editing, validation. ID: data sharing, editing, validation. MS: methodology, writing, editing, validation. YA: data sharing, editing, validation. NR: conceptualisation, methodology, writing, editing, validation, supervision.

Funding This work was partly funded by UNFPA/maternal and newborn health thematic fund (MHTF). Award/grant number: not applicable.

Competing interests None declared.

Patient consent for publication Not required.

Provenance and peer review Not commissioned; externally peer reviewed.

Data availability statement Data are available upon reasonable request. Most data used in this study are openly accessible through the indicated data sources in the 'Input geospatial data' section. Health facility names and geographical coordinates, as well as administrative boundaries are available on request to INSEED. Road data are available on request to the Direction de la Cartographie nationale et du cadastre of Togo. Data on barriers to movement are available on request to the Ministère de l'agriculture, de la production animale et halieutique of Togo.

Supplemental material This content has been supplied by the author(s). It has not been vetted by BMJ Publishing Group Limited (BMJ) and may not have been peer-reviewed. Any opinions or recommendations discussed are solely those of the author(s) and are not endorsed by BMJ. BMJ disclaims all liability and responsibility arising from any reliance placed on the content. Where the content includes any translated material, BMJ does not warrant the accuracy and reliability of the translations (including but not limited to local regulations, clinical guidelines, terminology, drug names and drug dosages), and is not responsible for any error and/or omissions arising from translation and adaptation or otherwise.

Open access This is an open access article distributed in accordance with the Creative Commons Attribution Non Commercial (CC BY-NC 4.0) license, which permits others to distribute, remix, adapt, build upon this work non-commercially, and license their derivative works on different terms, provided the original work is properly cited, appropriate credit is given, any changes made indicated, and the use is non-commercial. See: http://creativecommons.org/licenses/by-nc/4.0/.

ORCID iDs

Marta Schaaf http://orcid.org/0000-0002-7616-5966

Nicolas Ray http://orcid.org/0000-0002-4696-5313

\section{REFERENCES}

1 Human Reproduction Program, World Health Organization. Strategies toward ending preventable maternal mortality (EPMM. Geneva, Switzerland: World Health Organization, 2015. https://apps.who. int/iris/bitstream/handle/10665/153544/9789241508483_eng.pdf; jsessionid=AB036F2DFE7A4ABBB00BE525D91915BD? sequence $=1$

2 UNFPA. The maternal and newborn health thematic fund annual report 2018 - fund annual report 2018, 2019. Available: https://www. unfpa.org/sites/default/files/pub-pdf/013_MHTF_Annual_report_15online.pdf

3 Gabrysch S, Campbell OMR. Still too far to walk: literature review of the determinants of delivery service use. BMC Pregnancy Childbirth 2009;9:18.

4 Kyei-Nimakoh M, Carolan-Olah M, McCann TV. Access barriers to obstetric care at health facilities in sub-Saharan Africa-a systematic review. Syst Rev 2017;6:15.

5 World Health Organization, United Nations Population Fund, Mailman School of Public Health, Mailman School of Public Health. Monitoring emergency obstetric care: a Handbook. Geneva: World Health Organization, 2009.

6 Ebener S, Guerra-Arias M, Campbell J, et al. The geography of maternal and newborn health: the state of the art. Int J Health Geogr 2015;14:10

7 Noor AM, Gikandi PW, Hay SI, et al. Creating spatially defined databases for equitable health service planning in low-income countries: the example of Kenya. Acta Trop 2004;91:239-51.

8 Macharia PM, Ouma PO, Gogo EG, et al. Spatial accessibility to basic public health services in South Sudan. Geospat Health 2017;12:106-13.

9 Donohoe J, Marshall V, Tan X, et al. Evaluating and comparing methods for measuring spatial access to mammography centers in Appalachia (Re-Revised). Health Serv Outcomes Res Methodol 2016;16:22-40.

10 Neutens T. Accessibility, equity and health care: review and research directions for transport geographers. J Transp Geogr 2015;43:14-27.

11 Ray N, Ebener S. AccessMod 3.0: computing geographic coverage and accessibility to health care services using anisotropic movement of patients. Int J Health Geogr 2008;7:17.

12 Alegana VA, Wright JA, Pentrina U, et al. Spatial modelling of healthcare utilisation for treatment of fever in Namibia. Int $J$ Health Geogr 2012;11:13.

13 Aoun N, Matsuda H, Sekiyama M. Geographical accessibility to healthcare and malnutrition in Rwanda. Soc Sci Med 2015;130:135-45.

14 Costa C, Santana P, Almendra R. And when there is no information? the case of São tomé and Principe. International Conference on sustainability Measurment and modeling; Terrassa, Spain, 2009. Available: https://www.researchgate.net/publication/270507560 And_when_there_is_no_information_The_case_of_Sao_tome_and_ Principe

15 Fisher RP, Myers BA. Free and simple GIS as appropriate for health mapping in a low resource setting: a case study in eastern Indonesia Int J Health Geogr 2011;10:11.

16 Munoz UH, Kallestal C. Geographical accessibility and spatial coverage modeling of the primary health care network in the Western Province of Rwanda. Int J Health Geogr 2012;11:11.

17 Ouma PO, Maina J, Thuranira PN, et al. Access to emergency hospital care provided by the public sector in sub-Saharan Africa in 2015: a geocoded inventory and spatial analysis. Lancet Glob Health 2018;6:e342-50.

18 Juran S, Broer PN, Klug SJ, et al. Geospatial mapping of access to timely essential surgery in sub-Saharan Africa. BMJ Glob Health 2018;3:e000875.

19 Schmitz MM, Serbanescu F, Kamara V, et al. Did saving mothers, giving life expand timely access to lifesaving care in Uganda? A spatial District-Level analysis of travel time to emergency obstetric and newborn care. Global Health: Science and Practice 2019;7:S151-67.

20 Ebener S, Stenberg K, Brun M, et al. Proposing standardised geographical indicators of physical access to emergency obstetric and newborn care in low-income and middle-income countries. BMJ Glob Health 2019;4:e000778.

21 Say L, Chou D, Gemmill A, et al. Global causes of maternal death: a who systematic analysis. Lancet Glob Health 2014;2:e323-33.

22 The World Bank Group. Togo - Data, 2020. Available: https://data. worldbank.org/country/TG

23 Central Intelligence Agency. Africa - Togo - The World Factbook Central Intelligence Agency, 2020. Available: https://www.cia.gov/ the-world-factbook/countries/togo/

24 INSEED. Mics 6 Togo. Lomé, Togo, 2017. Available: https:// washdata.org/report/togo-2017-mics-report-v2 
25 Ministère de la Santé et de l'Hygiène publique. Plan national de Développement 2017-2022. Lomé, Togo, 2017. Available: http:// extwprlegs1.fao.org/docs/pdf/Tog184007.pdf

26 Brun M, Monet JP, Agbigbi Y, et al. Implementation manual for developing a national network of maternity units - improving emergency obstetric and newborn care (EmONC). UNFPA, New York, 2020. Available: https://www.unfpa.org/featured-publication/ implementation-manual-developing-national-network-maternity-units

27 Ray N, Ebener S. AccessMod 5 user manual - user manual (English). Geneva, Switzerland: University of Geneva, 2020. https://docaccessmod.unepgrid.ch/display/EN/

28 Nichols BE, Girdwood SJ, Crompton T, et al. Impact of a borderless sample transport network for scaling up viral load monitoring: results of a geospatial optimization model for Zambia. J Int AIDS Soc 2018;21:9.

29 Département des transports du développement urbain et des TIC. Le secteur du transport au Togo - Bref aperçu. Groupe de la Banque Africaine de Développement, 2014. Available: https://www.afdb.org/ fileadmin/uploads/afdb/Documents/Publications/AfDB_-_Togo_-_ Note_sur_le_secteur_du_transport.pdf

30 Center for International Earth Science Information Network -

CIESIN - Columbia University, International Food Policy Research Institute - IFPRI, The World Bank. Global rural-urban mapping project, version 1 (GRUMPv1): urban extent polygons, revision 01. NASA socioeconomic data and applications center (SEDAC), 2017. Available: https://doi.org/10.7927/H4Z31WKF
31 Stewart BT, Tansley G, Gyedu A, et al. Mapping population-level spatial access to essential surgical care in Ghana using availability of bellwether procedures. JAMA Surg 2016;151:e161239.

3232 Ministère de l'agriculture. Barriers to movement, 2016. Available: https://agriculture.gouv.tg

33 Direction de la Cartographie nationale et du cadastre. Road network of Togo. Lomé, Togo 2016 https://www.dadc.gouv.tg

34 Jarvis A, Reuter $\mathrm{H}$, Nelson A. Hole-filled SRTM for the globe version 3, from the CGIAR-CSI SRTM 90m database, 2008. Available: http:// srtm.csi.cgiar.org

35 Worldpop, CIESIN. The spatial distribution of population with country total adjusted to match the corresponding UNPD estimate - Togo, 2013. Available: https://www.worldpop.org/geodata/listing? id $=69$

36 UNFPA-Togo. Priorisation et cartes des soins obstétricaux et néonatals d'urgence au Togo. Lomé, Togo; 2020. https://togo. unfpa.org/fr/publications/cartographie-des-soins-obstetricaux-etneonatals-durgence-au-togo-2019

37 INSEED. Administrative boundaries of Togo. Institut National de la Statistique et des Etudes Economiques et démographiques, Lomé, Togo; 2016. http://www.inseed.tg

38 Peters DH, Garg A, Bloom G, et al. Poverty and access to health care in developing countries. Ann N Y Acad Sci 2008;1136:161-71.

39 Kruk ME, Gage AD, Arsenault C, et al. High-Quality health systems in the sustainable development goals era: time for a revolution. Lancet Glob Health 2018;6:e1196-252. 